\title{
Introduction to the Policies and Strategies for Digital Government Minitrack
}

\author{
Peter Parycek \\ Danube-University Krems \\ peter.parycek@donau-uni.ac.at
}

\author{
Antonio Cordella \\ London School of Economics and Political Science \\ a.cordella@1se.ac.uk
}

\author{
Frank Bannister \\ Trinity College, Dublin \\ Frank.Bannister@tcd.ie
}

This minitrack offers a multidisciplinary forum to present cases and discuss theories associated with the design, implementation, management and evaluation of digital government. The minitrack invites submissions that contribute to the analysis and discussion of the impact of digital government on public sector, especially on the organization of government activities, the delivery of public services, and on the value these services deliver. The submissions of case studies demonstrating best practices in the design, management and evaluation of digital government policies and strategies as well as contributions exploring the issues associated with the design and deployment of policies and strategies that change the nature of the interactions between government and citizens, private sector organizations, and NGOs are very much encouraged. 